\title{
Dilemma of Inferior Turbinate Surgery
}

\author{
Khaled Mohamed Bofares \\ Otorhinolaryngology, Omar Almoukhtar University, Elbyda, Libya
}

Email address:

bofaresstat2012@yahoo.com

\section{To cite this article:}

Khaled Mohamed Bofares. Dilemma of Inferior Turbinate Surgery. Advances in Surgical Sciences. Vol. 3, No. 2, 2015, pp. 8-18. doi: $10.11648 /$ j.ass.20150302.11

\begin{abstract}
Background and objectives: Inferiorturbinate surgery is considered as one of most commonly performed surgery in rhinology. It is usually done to reduce the bulk of inferior turbinates. It can be conducted for different indications such as relieving the mechanical nasal obstruction due to hypertrophied inferior turbinates, or to achieving a sufficient nasal surgical access during endoscopic sinus surgery, or removing the inferior turbinates as a part of wide and complete resection of rhinosinus neoplastic lesions. The inferior turbinates have important role in the maintenance of nasal breathing function by providing the nasal valve mechanism necessary for the regulation of air flow through the nose. In spite of availability of wellestablished variable techniques for this surgery, the main goal of this surgery is yet not completely achieved. This could bean effect of different factors that are difficult to be predicted and controlled. Hence this pattern of surgery has become dilemmas in rhinology which need to be deeply evaluated and subsequently resolved. In order to evaluate and resolve this dilemma, this serial study was conducted prospectively. Patients and methods: 1337 patients aged 3 to -65 years suffering from hypertrophied inferior turbinates, presented with clinical pictures of mechanical nasal obstruction at ENT department - of Althowra central hospital and Al-tarahom private center Elbyda city- Libya between September 2005 to September 2014 they were operated by variable techniques of inferior turbinate surgery, namely sub-mucosal diathermy (SMD) ( $\mathrm{n}=864$ ), partial inferior turbinectomy (PIT) $(n=427), \mathrm{CO}_{2}$ laser vaporization of inferior turbinate $(\mathrm{n}=21)$, and turbinoplasty $(\mathrm{n}=25)$. Post-operative atrophic rhinitis, and persistence, or recurrence of mechanical nasal obstruction the outcomes are that were studied in relation to different factors to shed-light on existing dilemma. Results and Conclusion: Proper selection of patient for this pattern of surgery is considered one of the main aspects of this issue and one of significant steps towards resolving of this dilemma. On the other hand, type of the technique for this surgery is an important selection criterion. In addition the amount of the inferior turbinate needed to be resected must be decided.
\end{abstract}

Keywords: Inferior Turbinate Surgery, Inferior Turbinectomy, Sub-Mucosal Diathermy, Turbinoplasty

\section{Introduction}

The inferior turbinate surgery is one of the most common surgical procedures performed in rhinology. It represents type of surgery, which is aimed basically at reduction of inferior turbinate bulk. Hence this type of surgery is considered as a very effective modality of surgery in relieving mechanical nasal obstruction due to hypertrophied inferior turbinate. There have been a lot of trials during past centuryto create new and more advanced manners of this important procedure. In deed all these trials were targeted for the purpose of the improvement of outcomes of this surgery. The cornerstone for improvement of outcomes of this surgery will be via the maintenance of optimum size for the inferior turbinates ${ }^{(1-20)}$. Anatomically as well as functionally speaking, the inferior turbinates are considered as very significant anatomical structures that act through their size and position to preserve one of the primary and vital functions of the nose which is the sufficient nasal breathing. This can be achieved by committing the normal nasal valve mechanism at the most anterior part of nasal cavity facilitatingeddy current type flow of the air ${ }^{(1-20)}$. Therefore the difficulties for preservation of unique size of inferior turbinatesisthe primary reason for this dilemma ${ }^{(10-27)}$.

There are variable etiologies for inferior turbinate hypertrophy which could be allergic rhinitis, rhinitis medicamentosa, vasomotor rhinitis, chronic hypertrophic rhinitis, and chronic infective rhinitis as fungal rhinitis. As it is well established that all previously mentioned causes can be treated and controlled sufficiently by medical treatment before the decision is made for any surgical interventions ${ }^{(1-53)}$.

On the other hand, broadly speaking the indications for 
inferior turbinate surgery can be classified as: a) for relieving of mechanical nasal obstruction due to confirmed persistent inferior turbinates hypertrophy, b) for providing a sufficient surgical access during certain internal nasal surgical procedures as functional endonasal endoscopic or microscopic sinus surgery, and c) as a part of wide resection for eradication of lateral nasal wall neoplastic lesions ${ }^{(1-60)}$.

In fact, during the last century as well as in the present century, one of the developing aspects in the rhinology is the inferior turbinate surgery. Therehave been many modalities of this surgery performed namely; submucosal diathermy, partial inferior turbinectomy, $\mathrm{CO}_{2}$ laser vaporization, Argon laser vaporization, turbinoplasty, and lateral nasal wall lateralization. Each of these procedures have advantages and disadvantages which need to be considered for each patient who is a candidate for inferior turbinate surgery to improve postoperative outcomes of this surgery. For some, there will be certain difficulties which may interfere with the proper selection of most suitable modality for each particular patient and subsequently the achieved sequels of this surgery will not be as considered therefore this type of surgery was described as one of the biggest dilemmas in rhinology ${ }^{(1-35)}$.

Thus this serial study was aimed as a prospective analytic study to resolve this dilemma as much as possible. In this study, we have made an attempt to put a frame-work for the solution of this dilemma by finding answers for these difficult questions:

Q1-Which patient can be considered as most suitable patient for this surgery?

Q2- Which modality of this surgery will be selected as most unique technique for this particular patient?

Q3- How much the bulk of inferior turbinate is recommended to be removed for the purpose of maintenance of sufficient size and contour of it?

Q4- As a trial to maintain the proper size and contour of inferior turbinate, is it advisable to perform concomitant septoplasty with inferior turbinate surgery?

\section{Patients and Methods}

1337 patients aged 3-65 years of persistent inferior turbinates hypertrophy due to different causes namely allergic rhinitis, rhinitis medica-mentosa, and vasomotor rhinitis, presented with mechanical nasal obstruction that not responding to enough medical treatment at ENT department - Althowra central hospital and Altarahom private center Elbyda city - Libya at period in between September 2005 to September 2014 who operated by different techniques of inferior turbinate surgery, namely sub-mucosal diathermy (SMD) ( $\mathrm{n}=864)$, partial inferior turbinectomy (PIT) $(n=427)$, $\mathrm{CO}_{2}$ laser vaporization of inferior turbinate $(\mathrm{n}=21)$, and turbinoplasty $(n=25)$. The mechanical nasal obstruction was confirmed clinically by the gross appearance of inferior turbinates at pre-operative anterior rhinoscopic as well as endoscopic evaluation as enlarged turbinates that occupied more than one-third of nasal lumen, with non-shiny, thick and pale mucosa, in addition to postulation of positive
Cottle's sign. According to intra-operative performed technique, SMD group was divided into three sub-groups (two points sub-group, three points sub-group, and four points sub-group) in reference to points of cauterization. The PIT group was classified according to the amount of resected tissue into three sub-groups (sub-group-A that include those patients who underwent resection of one-third of hypertrophied inferior turbinate, sub-group-B that include those who underwent for the resection of two-thirds of hypertrophied inferior turbinate, and sub-group-C that include patients who underwent for the subtotal resection of hypertrophied inferior turbinate), in addition $\mathrm{CO}_{2}$ laser vaporization group was categorized in relation to the used laser power into four sub-groups (sub-goup1, sub-group2, sub-group3, and sub-group4) which include those patients who underwent $\mathrm{CO}_{2}$ laser vaporization with different powers in Watts $(2,3,4$, and 5 Watts consecutively). On the other hand, the part of patients who interfered with SMD and PIT were operated concomitantly with septoplasty $(n=355, n=$ 235 consecutively), and compared to those who operated by solitary SMD and PIT $(n=509, n=192$ consecutively) to assess the effect of concomitant septoplasty on outcomes of inferior turbinate surgery. The outcomes of the surgery were studied and compared between the groups and sub-groups in relation to different patients' demographic, environmental, habitual, socio-economic, pathological as well as technical factors. The patients postoperatively were evaluated throughout first week for any nasal bleeding and followed up for 3-36 months to be assessed for common late complications of the surgery which are mainly the persistence or recurrence of mechanical nasal obstruction, and post-operative atrophic rhinitis. The nasal obstruction was assessed post-operatively by elucidation of any olfactory impairment in addition to application of cottle's test and atrophic rhinitis was diagnosed clinically by recognition of local atrophic changes.

In accordance and from economic point of view the expense of each technique was assessed in relation todrugs consumption (this was including anesthesia drugs, systemic antibiotics, analgesic drugs, intravenous fluids, postoperative local irrigation solutions, and sometimes anticoagulant drugs as tranexamic acid which may be required to be administered for patients with uncontrolled post-operative epistaxis), any expense related to specific machine which is used in the inferior turbinate surgery technique as $\mathrm{CO}_{2}$ laser machine, used local nasal packs, expense related to patient's word admission, and finally expense related to patient post-operative follow-up. The total price for each technique was roughly calculated in Libyan dinars and equaled to American dollars.

An informed consent was taken from the patients involved in the research prior to their participation.

Data were expressed by using descriptive analysis as means + standard error of mean (s. e. m) and percentages, test of significance was carried out, using Chi-square test and two way analysis of variance. A probability less than 0.05 was considered as significant, the degree of significance was 
determined by using level of standard deviation test. Student -t- test was used for dependent sample, as well as contingency coefficient was calculated as measurement of association between nominal variables.

\section{Results}

As shown in (Figure - I\& II) the incidence of postoperative nasal bleeding and atrophic rhinitiswas correlated to two significant factors which are the age of patient and the type of performed technique, it was found that the PIT increased significantly the risk of post-operative bleeding and atrophic rhinitis up to $(20 \%)$ and $(35 \%)$ consecutively among elderly patients as compared to SMD and $\mathrm{CO}_{2}$ laser vaporization $(\mathrm{P}<0.05)$. On the other hand, as illustrated in (Figure - III)the incidence of post-operative recurrence of hypertrophied inferior turbinates was correlated to the patient related environmental as well as habitual factors, it was found that SMD and $\mathrm{CO}_{2}$ laser vaporization are associated with higher percentage of recurrence (30\% and $80 \%)$ consecutively as compared to PIT among heavy smoking patients as well as those patients with history of frequent exposure to allergic rhinitis inducing allergens $(\mathrm{P}<0.05)$. In accordance the (Table-I) postulated the effect of patients' local health status on outcomes of the inferior turbinate surgery,it was found that the patients with allergic rhinitis and vasomotor rhinitis who interfered by PIT as well as turbinoplasty showed a significant longstanding improvement may reach up to $93 \%$ as compared to those who interfered by SMD and $\mathrm{CO}_{2}$ laser vaporization $(\mathrm{P}<0.05)$. As demonstrated in (Table - II) the effect of patients' general health status in relation to the type of performed technique outcomes, it was confirmed that the patients with uncontrolled systemic hypertension had a significant raising in the risk of post-operative epistaxis after PIT as compared to other techniques and also those patients with uncontrolled diabetes mellitus shown higher risk of recurrence of nasal obstruction after SMD as well as $\mathrm{CO}_{2}$ laser vaporization as compared to other techniques $(\mathrm{P}<0.05)$.on the other hand, (Figure - IV) was elucidated the comparison between different techniques in relation to intraoperative time consumption, it was found that the duration of turbinoplasty was significantly longer as compared to PIT, $\mathrm{CO}_{2}$ laser vaporization, and SMD technique which was associated with the minimal duration $(\mathrm{P}<0.05)$. Therefore from economic point of view, as illustrated at (Table-III) the $\mathrm{CO}_{2}$ laser vaporization can be considered significantly with higher expense as compared to other techniques $(\mathrm{P}<0.05)$. From the other aspect, technically speaking as can be notedfrom (Table - IV) the amount of direct or indirect reduction of inferior turbinate bulk had a significant effect on outcomes of the performed procedure, and as it is presented at the same table these results was correlated with number of cauterization points in $\mathrm{SMD}$, the used power in $\mathrm{CO}_{2}$ laser vaporization, as well as the resected size of inferior turbinate among PIT, it was found that the three sub-groups of SMD technique according to number of cauterization points (two points $\backslash$ three points $\backslash$ four points) did not show any significant difference in relation to post-operative outcomes namely local atrophic changes and persistent or recurrence of nasal obstruction $(P>0.5)$. In accordance the risk of post-operative atrophic rhinitis as well as persistence or recurrent nasal obstruction increased significantly among third sub-group of PIT as compared to other two sub-groups $(\mathrm{P}<0.05)$. In addition it was observed that there is no direct proportional relation-ship between the used power of $\mathrm{CO}_{2}$ laser and postoperative outcomes $(\mathrm{P}>0.5)$. On the other hand, as shown in (Table- V) there was significant improvement for outcomes of SMD as well as PIT if they are performed concomitantly with septoplasty procedure $(\mathrm{P}<0.05)$.

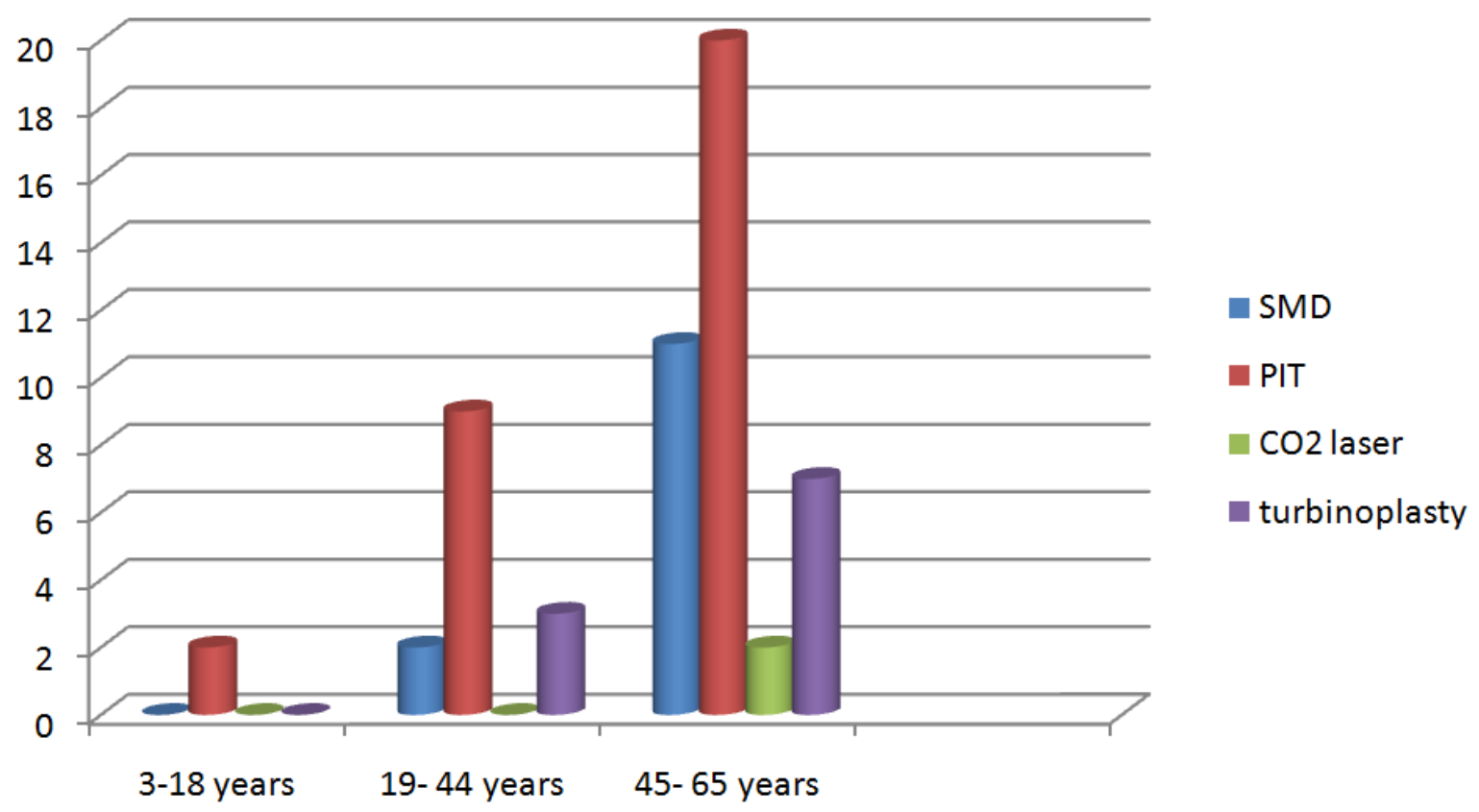

Figure I. The incidence of post-operative epistaxis (\%) in relation to type of procedure and patients' age $(P<0.05)$. 


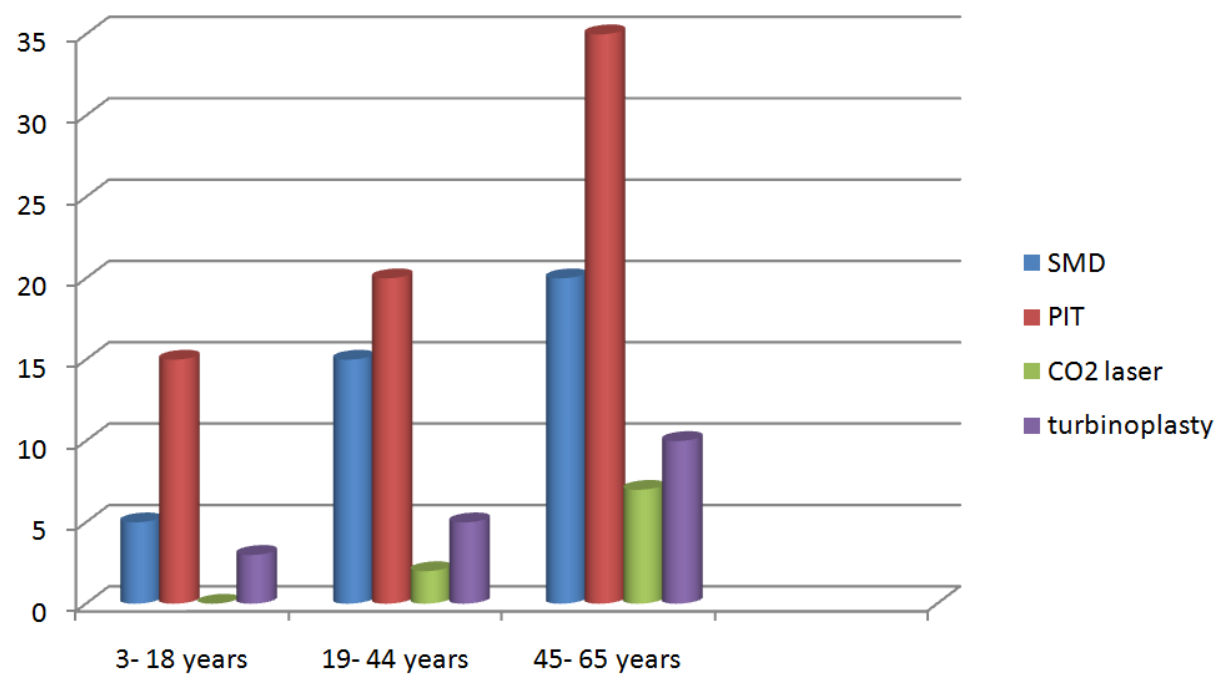

Figure II. The incidence of post-operative atrophic rhinitis (\%) in relation to type of procedure and patients' age $(P<0.05)$.

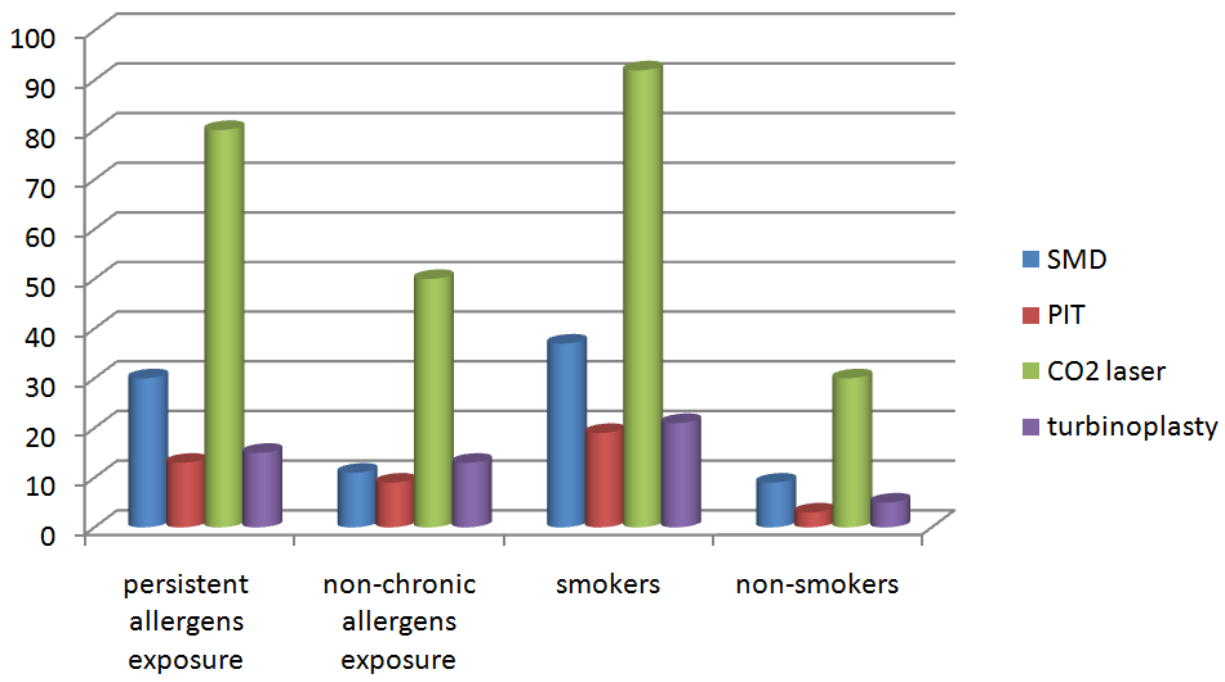

Figure III. The incidence of post-operative recurrence of hypertrophied inferior turbinates (\%) in correlation with the patient related environmental as well as habitual factors $(P<0.05)$.

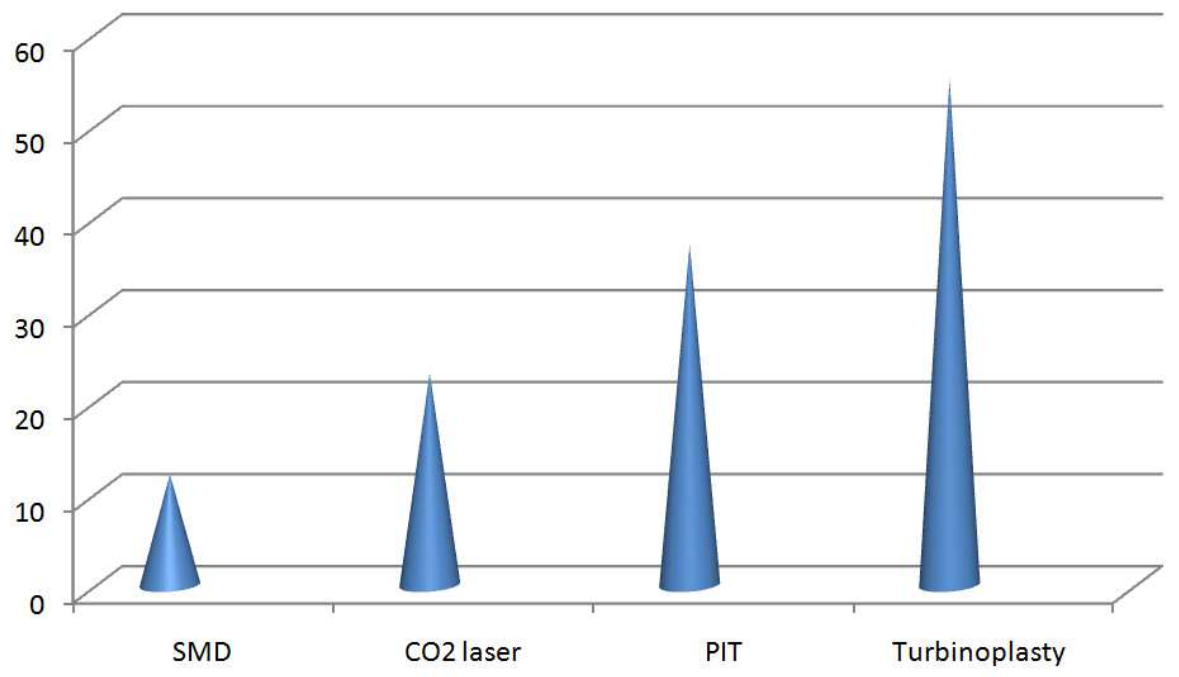

Figure IV. The comparison between different techniques in relation to intraoperative time consumption in minutes $(P<0.05)$. 
Table I. Effect of patients' local health status on the persistence of post-operative relief of mechanical nasal obstruction for three years after inferior turbinate surgery $(P<0.05)$.[ARn means number of cases with allergic rhinitis; VMRnmeans number of cases with vasomotor rhinitis]

\begin{tabular}{|c|c|c|c|c|c|}
\hline \multirow[b]{2}{*}{$\begin{array}{l}\text { Type of local } \\
\text { pathology }\end{array}$} & \multicolumn{5}{|c|}{ Percentage (\%) of persistence of nasal patency improvement for 36 months in relation to type of procedure } \\
\hline & $\begin{array}{l}\text { SMD }(N=864) \\
{[A R n=536 \& V M R n=264]}\end{array}$ & $\begin{array}{l}\text { PIT }(N=427) \\
{[A R n=269 \& V M R n=133]}\end{array}$ & $\begin{array}{l}\mathrm{CO}_{2} \text { laser }(\mathrm{N}=21) \\
{[\mathrm{ARn}=13 \& \mathrm{VMRn}=8]}\end{array}$ & $\begin{array}{l}\text { Turbinoplasty }(\mathrm{N}=25) \\
{[\mathrm{ARn}=20 \& \mathrm{~V} M \mathrm{MR}=5]}\end{array}$ & $\begin{array}{l}\text { Total } \\
\text { n \& } \%\end{array}$ \\
\hline Allergic rhinitis (AR) & $(\mathrm{n}=306)$ & $(n=250)$ & $(\mathrm{n}=8)$ & $(n=16)$ & $(\mathrm{n}=580)$ \\
\hline$(\mathrm{N}=838)$ & $57 \%$ & $93 \%$ & $63 \%$ & $80 \%$ & $69 \%$ \\
\hline Vasomotor rhinitis & $(n=129)$ & $(\mathrm{n}=118)$ & $(n=3)$ & $(n=4)$ & $(\mathrm{n}=254)$ \\
\hline$(\mathrm{VMR})(\mathrm{N}=410)$ & $49 \%$ & $89 \%$ & $37 \%$ & $83 \%$ & $62 \%$ \\
\hline Total & $(\mathrm{n}=435)$ & $(n=368)$ & $(\mathrm{n}=11)$ & $(\mathrm{n}=20)$ & $(\mathrm{n}=834)$ \\
\hline $\mathrm{N}=1248$ & $54 \%$ & $92 \%$ & $53 \%$ & $80 \%$ & $67 \%$ \\
\hline
\end{tabular}

Table II. Effect of patients' general health status on outcomes of inferior turbinate surgery $(P<0.05)$. [HTNn means number of cases with systemic hypertension; DMnmeans number of cases with diabetes mellitus].

\begin{tabular}{|c|c|c|c|c|c|c|c|c|}
\hline \multirow{3}{*}{$\begin{array}{l}\text { Type of general } \\
\text { pathology }\end{array}$} & \multicolumn{8}{|c|}{$\begin{array}{l}\text { Percentage (\%) of post-operative epistaxis (E) and recurrence of nasal obstruction (RNO) at each procedure in relation } \\
\text { to patients' general health status }\end{array}$} \\
\hline & \multicolumn{2}{|c|}{$\begin{array}{l}\text { SMD }(\mathrm{N}=864) \\
{[\mathrm{HTNn}=47 \& D M n=81]}\end{array}$} & \multicolumn{2}{|c|}{$\begin{array}{l}\text { PIT }(\mathrm{N}=427) \\
{[\mathrm{HTNn}=13 \& \mathrm{DMn}=37]}\end{array}$} & \multicolumn{2}{|c|}{$\begin{array}{l}\mathrm{CO}_{2} \text { laser }(\mathrm{N}=21) \\
{[\mathrm{HTNn}=3 \& \mathrm{DMn}=2]}\end{array}$} & \multicolumn{2}{|c|}{$\begin{array}{l}\text { Turbinoplasty }(\mathrm{N}=25) \\
{[\mathrm{HTNn}=4 \& \mathrm{DMn}=2]}\end{array}$} \\
\hline & $\mathbf{E}$ & RNO & $\mathbf{E}$ & RNO & $\mathbf{E}$ & RNO & $\mathbf{E}$ & RNO \\
\hline \multirow{4}{*}{$\begin{array}{l}\text { Systemic hypertension } \\
(\mathrm{N}=67) \\
\text { Diabetes mellitus } \\
(\mathrm{N}=122)\end{array}$} & $\mathrm{n}=13$ & $\mathrm{n}=18$ & $\mathrm{n}=12$ & $\mathrm{n}=2$ & $\mathrm{n}=0$ & $\mathrm{n}=1$ & $\mathrm{n}=2$ & $\mathrm{n}=0$ \\
\hline & $27 \%$ & $39 \%$ & $91 \%$ & $13 \%$ & $0 \%$ & $34 \%$ & $50 \%$ & $0 \%$ \\
\hline & $\mathrm{n}=15$ & $\mathrm{n}=70$ & $\mathrm{n}=27$ & $\mathrm{n}=6$ & $\mathrm{n}=0$ & $\mathrm{n}=0$ & $\mathrm{n}=0$ & $\mathrm{n}=0$ \\
\hline & $19 \%$ & $87 \%$ & $73 \%$ & $17 \%$ & $0 \%$ & $0 \%$ & $0 \%$ & $0 \%$ \\
\hline
\end{tabular}

Table III. The comparison between the expenses of different techniques of inferior turbinate surgery $(P<0.05)$.

\begin{tabular}{|c|c|c|c|c|}
\hline \multirow[t]{2}{*}{ The items } & \multicolumn{4}{|c|}{$\begin{array}{l}\text { The expenses for different inferior turbine surgery techniques in Libyan dinars (mean } \pm \text { standard error of mean } \\
\text { (s. e. m)) }\end{array}$} \\
\hline & SMD & PIT & $\mathrm{CO}_{2}$ laser & turbinoplasty \\
\hline Drugs & $36 \pm 4.7$ & $108 \pm 5.3$ & $55 \pm 7.9$ & $103 \pm 1.9$ \\
\hline Nasal packing & $15 \pm 11.5$ & $33 \pm 0.2$ & 0 & $31 \pm 0.5$ \\
\hline Patients word stay & $126 \pm 3.9$ & $299 \pm 0.7$ & $44 \pm 1.2$ & $209 \pm 0.3$ \\
\hline Specific machine expense & 0 & 0 & $139 \pm 4.1$ & 0 \\
\hline Post-operative patient follow-up & $35 \pm 4.3$ & $77 \pm 6.3$ & $43 \pm 5.7$ & $53 \pm 0.7$ \\
\hline The total in American dollars & $106 \pm 2.9$ & $258 \pm 3.7$ & $140 \pm 2.5$ & $198 \pm 0.16$ \\
\hline
\end{tabular}

Table IV. The outcomes of $\mathrm{CO}_{2}$ laser vaporization of hypertrophied inferior turbinate (\%) in relation to used power in Watts $(P<0.05)$.

\begin{tabular}{|c|c|c|c|c|}
\hline \multirow{2}{*}{ Outcomes of technique } & \multicolumn{4}{|c|}{$\begin{array}{l}\text { The outcomes of } \mathrm{CO}_{2} \text { laser vaporization of hypertrophied inferior turbinate (\%) in relation to used } \\
\text { power in Watts }(\mathrm{N}=21)\end{array}$} \\
\hline & $\begin{array}{l}2 \text { Watts } \\
(n=5)\end{array}$ & $\begin{array}{l}3 \text { Watts } \\
(n=6)\end{array}$ & $\begin{array}{l}4 \text { Watts } \\
(n=5)\end{array}$ & $\begin{array}{l}5 \text { Watts } \\
(n=5)\end{array}$ \\
\hline Local atrophic changes & $\begin{array}{l}40 \% \\
(\mathrm{n}=2)\end{array}$ & $\begin{array}{l}17 \% \\
(n=1)\end{array}$ & $\begin{array}{l}20 \% \\
(\mathrm{n}=1)\end{array}$ & $\begin{array}{l}60 \% \\
(\mathrm{n}=3)\end{array}$ \\
\hline $\begin{array}{l}\text { Persistence or recurrence of mechanical } \\
\text { nasal obstruction }\end{array}$ & $\begin{array}{l}60 \% \\
(\mathrm{n}=3)\end{array}$ & $\begin{array}{l}34 \% \\
(\mathrm{n}=2)\end{array}$ & $\begin{array}{l}60 \% \\
(\mathrm{n}=3)\end{array}$ & $\begin{array}{l}80 \% \\
(n=4)\end{array}$ \\
\hline
\end{tabular}

Table $\boldsymbol{V}$. The comparativeillustration of outcomes of SMD as well as PIT with and without septoplasty $(P<0.05)$.

\begin{tabular}{|c|c|c|c|c|}
\hline \multirow[t]{2}{*}{ Outcomes } & \multicolumn{2}{|c|}{$\begin{array}{l}\text { Percentage of outcomes with septoplasty } \\
\mathrm{N}=590\end{array}$} & \multicolumn{2}{|c|}{$\begin{array}{l}\text { Percentage of outcomes without septoplasty } \\
\mathrm{N}=701\end{array}$} \\
\hline & One point SMD $n=355$ & One-third PIT $n=235$ & Two point SMD n=509 & Two -thirds PIT $n=192$ \\
\hline Atrophic changes & 0 & $\begin{array}{l}2 \% \\
n=5\end{array}$ & $\begin{array}{l}31 \% \\
\mathrm{n}=158\end{array}$ & $\begin{array}{l}47 \% \\
n=90\end{array}$ \\
\hline Persistent nasal obstruction & 0 & 0 & $\begin{array}{l}12 \% \\
\mathrm{n}=61\end{array}$ & $\begin{array}{l}9 \% \\
\mathrm{n}=17\end{array}$ \\
\hline
\end{tabular}

\section{Discussion}

The inferior turbinate surgery is considered as a big issue in rhinology. Hence this pattern of surgery is frequently indicated and widely performed with a need of favorable outcomes. Though last two centuries many clinical studies have been conductedpresenting new techniques for better outcomes, it has been very difficult to decide which technique is most suitable for certain patients. It has been found that there are many factors responsible for that hinder selection of most appropriate manner of inferior turbinate surgery ${ }^{(15-65)}$. Thus this type of surgery can be classified as one of the dilemmas in rhinology and according to our experience the main points that in favor of this dilemma 
innovation are:

a) Which patient is a most suitable candidate for inferior turbinate surgery?

b) Which technique can be selected as the most appropriate technique for certain particular patient?

c) How much is it required to remove from the bulk of hypertrophied inferior turbinate?

d) Is the solitary inferior turbinate surgery sufficient to relieve the mechanical nasal obstruction or does it needs to be performed with the septoplasty as concomitant procedure to improve outcomes of the surgery?

In this serial study we tried to find out answers for all these questions. On the other hand, the inferior turbinatectomy can be conducted non-electively as a part of wide resection of sino-nasal neoplastic lesions ${ }^{(36-50)}$. Our discussion is to mainly highlight the elective category of this surgery. Basically there are five major criteria according to which the patient might be indicated for inferior turbinate surgery:

a) The patient has chronic nasal obstruction related presentations of five varieties: partial or complete inability to breathe through the nose, frequent or persistent opened mouth for mouth breathing, olfaction function impairment, sleep related breathing disorders, and recurrent sore throat, pharyngitis, as well as oral ulcers due to persistent mouth breathing.

b) The patient received sufficient medical therapy in form of local steroids, local nasal douching, systemic steroids, and systemic anti-histamines for enough time which is 3-6 months but the patient did not show any significant clinical improvement.

c) The patient confirmed locally by anterior rhinoscopic as well as endoscopic evaluations that has significant hypertrophied inferior turbinate which occupies more than one-third of nasal cavity.

d) The hypertrophied inferior turbinate grossly appears as enlarged turbinate with thick, pale, grayish-white, and non-shiny covering mucosa.

e) The significant nasal obstruction due to hypertrophied inferior turbinate must be elucidated objectively by positive rhino-metric evaluation, and $\backslash$ or positive Cottle's sign, and $\backslash$ or positive impairment of olfactory function.

Once an ideal candidate is selected for inferior turbinate surgery; the next step will be the selection of most suitable technique for that particular patient. Generally speaking there are five patterns of inferior turbinate surgical techniques namely; a) partial turbinectomy which can be done by lateral resection of maximum up to one-third of hypertrophied inferior turbinate either by using curved scissors, or shaver, or radio-frequency ablation, or co-ablation ${ }^{(1-20}$ and 37-71). b) submucosal diathermy, this technique is considered as old fashion for inferior turbinate surgery. It is performed by creation of electrical cauterization at multiple points (2-5 points) through sub-mucosal layer of hypertrophied inferior turbinate. This technique acts mainly by cauterization of submucosal venous sinusoids among hypertrophied inferior turbinate with active sensitization inflammatory process due to allergic rhinitis, vasomotor rhinitis, or rhinitis medicamentosa. Thus the sub-mucosal fibrosis will be induced subsequently as a reaction to venous sinusoids cauterization and this will result in the shrinkage of inferior turbinate bulk. However the submucosal diathermy technique was proved to be very effective and simple technique but still it is of no benefits among those patients with hypertrophied inferior turbinate due to increase in bulk of concha bone rather than soft tissue ${ }^{(1-20)}$. c) $\mathrm{CO}_{2}$ laser vaporization of hypertrophied inferior turbinate, this technique was confirmed to be very effective with minimal post-operative local atrophic changes as compared to other previously mentioned two techniques. It acts by same mechanism of submucosal diathermy through its penetration effect into sub-mucosal layer of hypertrophied inferior turbinate and as compared to submucosal diathermy technique it has less destructive effect on the mucosal glandular acini as well as venous sinusoids therefore the incidence of post-operative atrophic rhinitis after $\mathrm{CO}_{2}$ laser vaporization is limited but in the same time its action to relief the mechanical nasal obstruction due to hypertrophied inferior turbinate will be lesser as compared to other techniques ${ }^{(20-35)}$.d) turbinoplasty, simplythis technique can be described as that inferior turbinate surgical modality which is conducted via the reduction of bone bulk of inferior concha. In accordance this technique is aimed to maintain the mucosal cover of inferior turbinate therefore the eddy current mechanism of air flow by inferior turbinate mucosal lining will be preserved in addition to the maintenance of moisture consistency of inspired air by mucosal glandular acinic secretions thus the turbinoplasty is the technique which associated with minimal post-operative nasal atrophic changes. Although the turbinoplasty is the recommended technique for hypertrophied inferior turbinate due thickened concha bone but for some extent it can be performed even for reduction of inferior turbinate soft tissue ${ }^{(36-72)}$. e) lateral nasal wall lateralization, which was first described by Daniel simmen on 2013 and this technique is simply performed by submucosal resection of lateral nasal wall bone just in front to lacrimal sac and this can give sufficient access for more lateralization of ipsilateral inferior turbinate ${ }^{(72)}$.

In fact we observed throughout our long practical experience that the following of the recommendations which frequently come out from several old as well as recent studies regarding inferior turbinate surgeries did not sufficiently give the predicted results as those studies concluded. For this reason we tried through this planned serial study to suggest certain possible factors that may had been thought to be effective factors on the outcomes of this pattern of surgery and the further conclusions from this study can be roughly considered as a first step toward the resolving of this big dilemma in rhinology. Accordingly in this serial study these suggested factors were mainly correlated to the answer of the second question of this dilemma (Which technique that can be selected as most proper technique for certain particular patient?). Moreover these studied factors can be discussed as: a) Patient's age, generally speaking, the elderly patients 
showed higher incidence of post-operative epistaxis as well as the atrophic rhinitis among four performed procedures namely PIT, SMD, $\mathrm{CO}_{2}$ laser vaporization, and turbinoplasty as compared to the young ages. On the other hand, specifically speaking, the incidence of post-operative epistaxis as well as atrophic rhinitis significantly increased by interfering with PIT as compared to other inferior turbinate surgical techniques i.e. the risk of post-operative epistaxis and atrophic rhinitis is direct proportionally to increasing of patient's age. This can be explained by a scientific and basic-physiological fact that vascular related aging process among elderly patients contributes the main predisposing factor for the impairment of local homeostasis control after the surgery as well as the delay of proper healing process at the site of surgery, in addition to the significant decrease in the number of venous sinusoids and mucosal glandular acini at sub-mucosal layer of the turbinate among elderly patient due to local physiological aging changes too ${ }^{(1-20 \text { and } 37-71)}$. Thus PIT might not be considered as the most suitable technique for inferior turbinate surgery among old ages because technically speaking PIT can be described as highly invasive procedure that associated with cutting action and wide resection of the turbinate's soft tissue that may increase significantly the risk of intra-operative as well as post-operative bleeding in addition to the increasing of risk of post-operative local atrophic changes particularly among elderly patients ${ }^{(15-20)}$. b)Patient related habitual and environmental factors, the results of this study postulated that the incidence of post-operative recurrence of inferior turbinate hypertrophy increased significantly by smoking and chronic exposure to certain allergens as pollens, animal epithelials, house dust mites, and chemical irritants as compared to the non-smokers as well as those patients who are not frequently exposed to environmental irritants. In accordance the incidence of recurrence of inferior turbinate hypertrophy by smoking and persistent allergens exposure was significantly higher after $\mathrm{CO} 2$ laser vaporization as compared to other techniques this can be explained by the insufficient reduction of sub-mucosal venous sinusoids as the histological changes on the inferior turbinate mucosa after $\mathrm{CO} 2$ laser vaporization this will increase the incidence of the inferior turbinate re-congestion and subsequent hypertrophy as the result of $\operatorname{IgE}$-hypersensitivity reaction activation due to the persistent smoking and exposure to the allergens. On the other hand, the SMD, PIT, and turbinoplasty are associated with significant lowering of the incidence of inferior turbinate hypertrophy after the surgery this is because of obvious reduction of the number of sub-mucosal venous sinusoids due to sub-mucosal cauterization by SMD and enough tissue bulk resection by PIT as well as turbinoplasty techniques. Therefore $\mathrm{CO}_{2}$ laser vaporization might not be selected as most suitable technique for inferior turbinate surgery among smokers and those patients who live or work at contaminated environment ${ }^{(18-20 \text { and 23-27) }}$. c) Patient's local health status, this serial study confirmed that the local nasal pathological status of the patient may affect significantly the decision regarding the selection of most proper technique of inferior turbinate surgery i.e. those patients who presented as cases of allergic rhinitis and vasomotor rhinitis got significant long standing improvement regarding the patency of nose after PIT and turbinoplasty as compared to SMD and $\mathrm{CO}_{2}$ laser vaporization. This can be discussed in relation to the sufficient amount of tissue which resected either by PIT or turbinoplasty. On the other hand, the basic idea behind the performance of SMD as well as $\mathrm{CO}_{2}$ laser vaporization is the reduction of number of venous sinusoids and enhancement of diffuse fibrosis at the level of sub-mucosal layer of inferior turbinate either by cauterization effect of SMD or penetration effect of $\mathrm{CO}_{2}$ laser vaporization; these effects had been proved to be not sufficient to fulfill the adequate maintenance of optimum size of inferior turbinate because still there is risk of proliferation of the venous sinusoids and subsequent recurrence of congestion as well as hypertrophy of inferior turbinate due to the allergic or autonomic nervous system disturbance phenomena predisposition. Thus the most suitable techniques for inferior turbinate surgery among patients with allergic rhinitis or vasomotor rhinitis are PIT or turbinoplasty ${ }^{(1-51)}$. d) Patient's systemic health status, this presenting study demonstrated that the risk of epistaxis is increased after PIT among hypertensive patients as well as diabetic patients; this can be explained by extensive local tissue injury due to PIT as compared to other less invasive techniques. Moreover the SMD creates higher risk of recurrence of nasal obstruction among diabetic patients as compared to other techniques; this can be reasoned to that the patients with diabetes mellitus are more prone for local atrophic changes and diffuse fibrosis as compared to non-diabetic patients due to high incidence of local diabetic angiopathic changes this can result in functional nasal obstruction rather than mechanical nasal obstruction, in addition to the higher incidence of vasomotor rhinitis among diabetic patients as compared to non-diabetic patients this will increase the risk of post-operative recurrence of mechanical nasal obstruction due to inferior turbinate hypertrophy. Accordingly we can judge that the PIT is not the advised technique for hypertensive as well as diabetic patients and SMD is not the curable procedure for patient with diabetes mellitus ${ }^{(1-19)}$.

In accordance there is another important factor which may has significant interaction for rooting of this dilemma namely the socio-economic factor. As it was elucidated at this serial study and via the rough evaluation of different economic aspects for each performed technique including the expense of used drugs, nasal packing, patient word stay, specific machine expense, and post-operative patient follow-up it was found that PIT and turbinoplasty had higher prices as compared to SMD as well as $\mathrm{CO}_{2}$ laser vaporization. Although the machine expense for $\mathrm{CO}_{2}$ laser vaporization is very significantly higher but still the total price is obviously lower as compared to other procedures. This can be discussed in relation to the other aspects rather than the machine expense i.e. PIT and turbinoplasty are considered as more invasive techniques which consume longer intra-operative duration therefore there will be more utilization of intra- 
operative anesthesia drugs in addition to certain specific drugs which might be needed to be administrated as tranxiemic acid for purpose of epistaxis control which of higher incidence among these two procedures ${ }^{(20-45)}$. On the other hand, patients after PIT as well as turbinoplasty need to be observed and cared more as compared to other techniques this will result in the prolongation of patient's post-operative stay at word. Also the patients after PIT and turbinoplasty need frequent follow-up sessions after their discharge this is because of high tendency for recurrent local dryness and crusts formation during first 4-6 weeks post-operatively which may predispose to infective rhinitis that result insubsequent healing by scaring and synaechia creation, for this reason the repetitive sessions of local irrigation and suction- clearance after PIT as well as turbinoplasty are recommended to reduce all previously mentioned risks. However the PIT and turbinoplasty are considered as very effective technique for the surgical management of persistent mechanical nasal obstruction due to inferior turbinate hypertrophy but at the same time they are considered as expensive procedures as compared to $\mathrm{SMD}$ and $\mathrm{CO}_{2}$ laser vaporization $^{(20-45)}$

In the same manner, we thought that the used power during $\mathrm{CO}_{2}$ laser vaporization constitutes one of important issues which may play a role in building-up of this big dilemma thus we tried via this clinical study to assess which is the most suitable power for $\mathrm{CO}_{2}$ laser vaporization. As it was illustrated at the results of this serial study the power of 3-4 watts were associated with lower incidence of post-operative atrophic rhinitis as well as persistence or recurrence of nasal obstruction as compared to lower powers which had been proved with significantly high incidence of post-operative persistent or recurrent nasal obstruction and higher powers which showed significant raising in the incidence of both post-operative atrophic rhinitis as well as persistence or recurrence of nasal obstruction. These observations can be explained by inability of low powers to destroy sufficient number of sub-mucosal venous sinusoids that may increase the risk of persistence and recurrence of mechanical nasal obstruction due to the inferior turbinate congestion and hyperemia and on the other hand the high powers are more destructive powers that lead to extensive venous sinusoids and glandular acini loss this will result in higher incidence of local atrophic changes after the surgery which can be considered as main cause for persistence or recurrence of functional nasal obstruction ${ }^{(19-33)}$.

From the other aspect, we tried at our serial clinical trial to evaluate whether the concomitant septoplasty has any role regarding improvement of outcomes of inferior turbinate surgery, in accordance we found that the performance of septoplasty even for mild deviated nasal septumas bothersome procedure with inferior turbinate surgery may improve significantly the outcomes of this surgery and this can be explained simply by the reduction of points of cauterization among SMD cases and limitation of the tissue resection among PIT cases therefore the risk of postoperative atrophic rhinitis and subsequent functional nasal obstruction is significantly decreased in addition that the patient get important relieve regarding the mechanical nasal obstruction because of the interfering with both deviated septum as well as hypertrophied inferior turbinate ${ }^{(53)}$.

Finally we can conclude to that really the inferior turbinate surgery is considered as one of big dilemmas at rhinology and because it is widely conducted surgery thus always it needs frequent research to resolve all possible associated problems and issues. The cornerstone of this dilemma is how to avoid the adverse outcomes of inferior turbinate surgery mainly post-operative epistaxis as early complication and atrophic rhinitis as well persistent or recurrent nasal obstruction as late complications. As it can be noted from the results of this serial study which tried to evaluate different patterns of inferior turbinate surgery and correlated with variable groups of factors the proper selection of most suitable candidate for this surgery is very necessary and we mean by suitable candidate that the patient who is strongly indicated for this surgery, in addition the proper selection of the most suitable technique is another significant key point toward the resolving of this dilemma. In accordance and as suggested recommendation the selection of proper technique needs to be based up on certain patient's related factors namely age, local as well as general health status, surrounding environment, habitus, and socio-economic status.

Although this study was well-controlled, long-standing, and of adequate number of cases but it may be considered as non-formative study regarding $\mathrm{CO}_{2}$ laser vaporization, and turbinoplasty because the number of operated cases among these two procedures is not sufficient as compared to other two procedures thus the comparative elucidations of $\mathrm{CO}_{2}$ laser vaporization as well as turbinoplasty with SMD and PIT will be non-conclusive therefore as other suggested recommendation the further clinical studies are advised to be committed to confirm these concepts which obtained from this presenting study and in the same time the new aims may be suggested to be postulated toward the resolving of this dilemma.

\section{References}

[1] Takeuchi H, Jawad M, Eccles R. Changes in unilateral nasal airflow in patients with seasonal allergic rhinitis measured in and out of season. Auris Nasus Larynx. 2000 Apr; 27(2):141-5.

[2] Jones AS, Lancer JM, Moir AA, Stevens JC. The effect of submucosal diathermy to the inferior turbinates on nasal resistance to airflow in allergic and vasomotor rhinitis. Clin Otolaryngol Allied Sci. 1985 Oct; 10(5):249-52.

[3] Fradis M, Malatskey S, Magamsa I, Golz A. Effect of submucosal diathermy in chronic nasal obstruction due to turbinate enlargement. Am J Otolaryngol. 2002 NovDec;23(6):332-6.

[4] von Haacke NP, Hardcastle PF. Submucosal diathermy of the inferior turbinate and the congested nose. ORL J Otorhinolaryngol Relat Spec. 1985; 47(4):189-93. 
[5] Talaat M, el-Sabawy E, Baky FA, Raheem AA.Submucous diathermy of the inferior turbinates in chronic hypertrophic rhinitis.J Laryngol Otol. 1987 May; 101(5):452-60.

[6] Jones AS, Lancer JM.Does submucosal diathermy to the inferior turbinates reduce nasal resistance to airflow in the long term?J Laryngol Otol. 1987 May; 101(5):448-51.

[7] Flanagan P, Eccles R.Physiological versus pharmacological decongestion of the nose in healthy human subjects. Acta Otolaryngol. 1998 Jan; 118(1):110-3.

[8] Lin Chuang Er Bi Yan Hou Ke Za Zhi.The effect of submucosal diathermy to the inferior turbinates on nasal airway resistance. 2001 Aug; 15(8):354-5.Chinese.

[9] Farmer SE, Quine SM, Eccles R.Efficacy of inferior turbinate coblation for treatment of nasal obstruction.J Laryngol Otol. 2009 Mar; 123(3):309-14. doi: 10.1017/S0022215108002818. Epub 2008 Jun 9.

[10] Ikeda K, Oshima T, Suzuki M, Suzuki H, Shimomura A.Functional inferior turbinosurgery (FITS) for the treatment of resistant chronic rhinitis. Acta Otolaryngol. $2006 \mathrm{Jul}$; 126(7):739-45.

[11] Cook JA, McCombe AW, Jones AS.Laser treatment of rhinitis-1 year follow-up.ClinOtolaryngol Allied Sci. 1993 Jun; 18(3):209-11.

[12] Thomas PL, John DG, Carlin WV.The effects of inferior turbinate outfracture on nasal resistance to airflow in vasomotor rhinitis assessed by rhinomanometry.J Laryngol Otol. 1988 Feb; 102(2):144-5.

[13] Wight RG, Jones AS, Beckingham E. Radical trimming of the inferior turbinates and its effect on nasal resistance to airflow.J Laryngol Otol. 1988 Aug; 102(8):694-6. No abstract available.

[14] Gindros G, Kantas I, Balatsouras DG, Kandiloros D, Manthos AK, Kaidoglou A.Mucosal changes in chronic hypertrophic rhinitis after surgical turbinate reduction.Eur Arch Otorhinolaryngol. 2009 Sep; 266(9):1409-16. doi: 10.1007/s00405-009-0916-9. Epub 2009 Jan 30

[15] Bäck LJ, Hytönen ML, Malmberg HO, Ylikoski JS. Submucosal bipolar radiofrequency thermal ablation of inferior turbinates: a long-term follow-up with subjective and objective assessment. Laryngoscope. 2002 Oct; 112(10):180612 .

[16] Chen YL, Tan CT, Huang HM.Long-term efficacy of microdebrider-assisted inferior turbinoplasty with lateralization for hypertrophic inferior turbinates in patients with perennial allergic rhinitis. Laryngoscope. $2008 \mathrm{Jul}$; 118(7):1270-4. doi: 10.1097/MLG.0b013e31816d728e.

[17] Elwany S, Gaimaee R, Fattah HA. Radiofrequency bipolar submucosal diathermy of the inferior turbinates. Am J Rhinol. 1999 Mar-Apr; 13(2):145-9.

[18] Chen YL, Liu CM, Huang HM.Comparison of microdebriderassisted inferior turbinoplasty and submucosal resection for children with hypertrophic inferior turbinates. Int J Pediatr Otorhinolaryngol. 2007 Jun; 71(6):921-7. Epub 2007 Apr 5.

[19] Mori S, Fujieda S, Yamada T, Kimura Y, Takahashi N, Saito H.Long-term effect of submucousturbinectomy in patients with perennial allergic rhinitis. Laryngoscope. 2002 May; 112(5):865-9.
[20] Mittelman H.CO2 laser turbinectomies for chronic, obstructive rhinitis.Lasers Surg Med. 1982; 2(1):29-36.

[21] Janda P, Sroka R, Betz CS, Grevers G, Leunig A.Ho:YAG and diode laser treatment of hyperplastic inferior nasal turbinates. Laryngorhinootologie. 2002 Jul; 81(7):484-90. German.

[22] Tanigawa T, Yashiki T, Hayashi K, Sato T. Carbon dioxide laser vaporization for turbinate: optimal conditions and indications. Auris Nasus Larynx. 2000 Apr; 27(2):137-40.

[23] Imamura S, Honda H.Carbon dioxide laser vaporization of the inferior turbinate for allergic rhinitis: short-term results. Ann Otol Rhinol Laryngol. 2003 Dec; 112(12):1043-9.

[24] Sroka R, Janda P, Killian T, Vaz F, Betz CS, Leunig A.Comparison of long term results after Ho:YAG and diode laser treatment of hyperplastic inferior nasal turbinates. Lasers Surg Med. 2007 Apr; 39(4):324-31.

[25] Sapçi T, Sahin B, Karavus A, Akbulut UG. Comparison of the effects of radiofrequency tissue ablation, $\mathrm{CO} 2$ laser ablation, and partial turbinectomy applications on nasal mucociliary functions. Laryngoscope. 2003 Mar;113(3):514-9.

[26] Fukutake T, Yamashita T, Tomoda K, Kumazawa T.Laser surgery for allergic rhinitis.Arch Otolaryngol Head Neck Surg. 1986 Dec; 112(12):1280-2.

[27] Lippert BM, Werner JA.CO2 laser surgery of hypertrophied inferior turbinates. Rhinology. 1997 Mar; 35(1):33-6.

[28] Ogawa T, Takeno S, Ishino T, Hirakawa K.Submucousturbinectomy combined with posterior nasal neurectomy in the management of severe allergic rhinitis: clinical outcomes and local cytokine changes. Auris Nasus Larynx. 2007 Sep; 34(3):319-26. Epub 2007 Apr 11.

[29] Orabi AA, Sen A, Timms MS, Morar P.Patient satisfaction survey of outpatient-based topical local anesthetic KTP laser inferior turbinectomy: a prospective study. Am J Rhinol. 2007 Mar-Apr; 21(2):198-202.

[30] Kawamura S, Fukutake T, Kubo N, Yamashita T, Kumazawa T.Subjective results of laser surgery for allergic rhinitis. Acta Otolaryngol Suppl.1993; 500:109-12.

[31] Takeno S, Osada R, Ishino T, Yajin K.Laser surgery of the inferior turbinate for allergic rhinitis with seasonal exacerbation: an acoustic rhinometry study.Ann Otol Rhinol Laryngol. 2003 May; 112(5):455-60.

[32] Jovanovic S, Dokic D.Nd:YAG laser surgery in treatment of allergic rhinitis. Laryngorhinootologie. 1995 Jul; 74(7):419-22. German.

[33] Janda P, Sroka R, Baumgartner R, Grevers G, Leunig A.Laser treatment of hyperplastic inferior nasal turbinates: a review. Lasers Surg Med. 2001; 28(5):404-13. Review.

[34] Schmidt J, Zalewski P, Olszewski J, Olszewska-Ziaber A. Histopathological verification of clinical indications to partial inferior turbinectomy. Rhinology. $2001 \mathrm{Sep}$; 39(3):147-50.

[35] Ishida H, Yoshida T, Hasegawa T, Mohri M, Amatsu M. Submucouselectrocautery following submucous resection of turbinate bone--a rationale of surgical treatment for allergic rhinitis. Auris Nasus Larynx. 2003 May; 30(2):147-52.

[36] Chhabra N, Houser SM. The surgical management of allergic rhinitis. Otolaryngol Clin North Am. 2011 Jun; 44(3):779-95, xi. doi: 10.1016/j.otc.2011.03.007. Review. 
[37] Englender M. Nasal laser mucotomy (L-mucotomy) of the inferior turbinates. J Laryngol Otol. 1995 Apr; 109(4):296-9.

[38] Jovanovic S, Dokic D.Does laser turbinectomy influence local allergic inflammation in the nose?Rhinology. 1996 Mar; 34(1):46-9.

[39] Vijay Kumar K, Kumar S, Garg S.A comparative study of radiofrequency assisted versus microdebrider assisted turbinoplasty in cases of inferior turbinate hypertrophy.Indian J Otolaryngol Head Neck Surg. 2014 Jan; 66(1):35-9. doi: 10.1007/s12070-013-0657-3. Epub 2013 May 5.

[40] Cavaliere M, Mottola G, Iemma M. Comparison of the effectiveness and safety of radiofrequency turbinoplasty and traditional surgical technique in treatment of inferior turbinate hypertrophy. Otolaryngol Head Neck Surg. 2005 Dec; 133(6):972-8.

[41] Rhee CS, Kim DY, Won TB, Lee HJ, Park SW, Kwon TY, Lee $\mathrm{CH}$, Min YG.Changes of nasal function after temperaturecontrolled radiofrequency tissue volume reduction for the turbinate.Laryngoscope. $2001 \mathrm{Jan}$; 111(1):153-8.

[42] Cassano M, Granieri C, Del Giudice AM, Mora F, FioccaMatthews E, Cassano P.Restoration of nasal cytology after endoscopic turbinoplasty versus laser-assisted turbinoplasty.Am J Rhinol Allergy. 2010 Jul-Aug; 24(4):310-4 doi: 10.2500/ajra.2010.24.3474.

[43] Lorenz KJ, Maier H.Microdebrider-assisted inferior turbinoplasty. Minimally invasive technique for the treatment of nasal airway obstruction caused by enlarged turbinates. HNO. 2013 Mar; 61(3):240-9. doi: 10.1007/s00106-012-25537. German.

[44] Yanez C, Mora N. Inferior turbinate debriding technique: tenyear results. Otolaryngol Head Neck Surg 2008; 138:170-5.

[45] Sacks R, Thornton MA, Boustred RN.Modified endoscopic turbinoplasty - long term results compared to submucosal electrocautery and submucosal powered turbinoplasty. Presented at the American Rhinologic Society, May 14, 2005.

[46] Passali D, Passali FM, Damiani V, Passali GC, Bellussi L. Treatment of inferior turbinate hypertrophy: a randomized clinical trial. Ann Otol Rhinol Laryngol. 2003, 112:683-688.

[47] Lai VWS, Corey JP.The objective assessment of nasal patency. Ear Nose Throat J. 1993, 72:395-400.

[48] Seeger J, Zenev E, Gundlach P, et al. Bipolar radiofrequencyinduced thermotherapy of turbinate hypertrophy: pilot study and 20 months follow-up. Laryngoscope.2001, 113:130-5.

[49] Jackson LE, Koch RJ. Controversies in the management of inferior turbinate hypertrophy: a comprehensive review. PlastReconstr Surg. 1999, 103:300-312.

[50] Hol MKS, Huizing EH. Treatment of inferior turbinate pathology: a review and critical evaluation of the different techniques. Rhinology.2000, 38:157-66.

[51] Camelo-Nunes IC, Solé D. Allergic rhinitis: indicators of quality of life. J Bras Pneumol. 2010, 36(1):124-33.

[52] Stewart MG, Witsell DL, Smith TL, Weaver EM, Yueh B, Hannley MT. Development and validation of the Nasal Obstruction Symptom Evaluation (NOSE) scale. Otolaryngol Head Neck Surg. 2004, 130(2):157-63.
[53] Stewart MG, Smith TL, Weaver EM, Witsell DL, Yueh B, Hannley MT, Johnson JT. Outcomes after nasal septoplasty: results from the Nasal Obstruction Septoplasty Effectiveness (NOSE) study. Otolaryngol Head Neck Surg. 2004, 130(3):283-90.

[54] Sapçi T, Sahin B, Karavus A, Akbulut UG. Comparison of the effects of radiofrequency tissue ablation, $\mathrm{CO} 2$ laser ablation, and partial turbinectomy applications on nasal mucociliary functions. Laryngoscope. 2003, 113(3):514-9.

[55] Cavaliere M, Mottola G, Iemma M. Comparison of the effectiveness and safety of radiofrequency turbinoplasty and traditional surgical technique in treatment of inferior turbinate hypertrophy. Otolaryngol Head Neck Surg. 2005, 133(6):972-8.

[56] Bhandarkar ND, Smith TL.Outcomes of surgery for inferior turbinate hypertrophy. Curr Opin Otolaryngol Head Neck Surg. 2010, 18(1):49-53.

[57] Leong SC, Eccles R. Inferior turbinate surgery and nasal airflow: evidence-based management. CurrOpinOtolaryngol Head Neck Surg. Feb 2010; 18(1):54-9.

[58] Hol MK, Huizing EH. Treatment of inferior turbinate pathology: a review and critical evaluation of the different techniques. Rhinology. Dec 2000; 38(4):157-66.

[59] Hanif J, Jawad SS, Eccles R.The nasal cycle in health and disease. Clin Otolaryngol Allied Sci. Dec 2000; 25(6):461-7.

[60] Farmer SE, Eccles R. Chronic inferior turbinate enlargement and the implications for surgical intervention.Rhinology. Dec 2006; 44(4):234-8.

[61] Bhandarkar ND, Smith TL. Outcomes of surgery for inferior turbinate hypertrophy. Curr Opin Otolaryngol Head Neck Surg. Feb 2010; 18(1):49-53.

[62] Ozcan KM, Gedikli Y, Ozcan I, Pasaoglu L, Dere H. Microdebrider for reduction of inferior turbinate: evaluation of effectiveness by computed tomography. J Otolaryngol Head Neck Surg. Aug 2008; 37(4):463-8.

[63] Chhabra N, Houser SM.The diagnosis and management of empty nose syndrome. Otolaryngol Clin North Am. Apr 2009; 42(2):311-30, ix.

[64] Batra PS, SeidenAM, Smith TL. Surgical management of adult inferior turbinate hypertrophy: a systematic review of the evidence. Laryngoscope. Sep 2009; 119(9):1819-27.

[65] Tanna N, Im DD, Azhar H, Roostaeian J, Lesavoy MA, Bradley JP, et al. Inferior turbinoplasty during cosmetic rhinoplasty: techniques and trends. Ann Plast Surg. Jan 2014; 72(1):5-8.

[66] Schumacher MJ. Nasal dyspnea: the place of rhinomanometry in its objective assessment. Am J Rhinol. Jan-Feb 2004; 18(1):41-6.

[67] Eccles R, Jawad MS, Jawad SS, Angello JT, Druce HM. Efficacy and safety of single and multiple doses of pseudoephedrine in the treatment of nasal congestion associated with common cold. Am J Rhinol. Jan-Feb 2005; 19(1):25-31.

[68] Garzaro M, Pezzoli M, Landolfo V, Defilippi S, Giordano C, Pecorari G. Radiofrequency Inferior Turbinate Reduction: Long-Term Olfactory and Functional Outcomes. Otolaryngol Head Neck Surg. Sep 202011. 
[69] Tanna N, Lesavoy MA, Abou-Sayed HA, Gruber RP. Septoturbinotomy. AesthetSurg J. Nov 1 2013; 33(8):1199205.

[70] Gupta A, Mercurio E, Bielamowicz S. Endoscopic inferior turbinate reduction: an outcomes analysis.Laryngoscope. Nov 2001; 111(11 Pt 1):1957-9.
[71] Lee JY, Lee JD. Comparative study on the long-term effectiveness between coblation- and microdebrider-assisted partial turbinoplasty. Laryngoscope. May 2006; 116(5):729-34.

[72] Daniel Simmen, Nick S. Jones. Lateral nasal wall lateralization and pyriformturbinoplasty. in: Manual of Endoscopic Sinus and Skull Base Surgery. 2013; 108a-b. 